\title{
Distinct Subtypes of Basolateral Amygdala Taste Neurons Reflect Palatability and Reward
}

\author{
Alfredo Fontanini, ${ }^{4 \star}$ Stephen E. Grossman, ${ }^{1,3 *}$ Joshua A. Figueroa, ${ }^{2}$ and Donald B. Katz ${ }^{1,2,3}$ \\ ${ }^{1}$ Volen National Center for Complex Systems, ${ }^{2}$ Department of Psychology, and ${ }^{3}$ Program in Neuroscience, Brandeis University, Waltham, Massachusetts \\ 02454, and ${ }^{4}$ Department of Neurobiology and Behavior, State University of New York at Stony Brook, Stony Brook, New York 11794
}

The amygdala processes multiple, dissociable properties of sensory stimuli. Given its central location within a dense network of reciprocally connected regions, it is reasonable to expect that basolateral amygdala (BLA) neurons should produce a rich repertoire of dynamical responses to taste stimuli. Here, we examined single BLA neuron taste responses in awake rats and report the existence of two distinct subgroups of BLA taste neurons operating simultaneously during perceptual processing. One neuron type produced long, protracted responses with dynamics that were strikingly similar to those previously observed in gustatory cortex. These responses reflect cooperation between amygdala and cortex for the purposes of processing palatability. A second type of BLA taste neuron may be part of the system often described as being responsible for reward learning: these neurons produced very brief, short-latency responses to rewarding stimuli; when the rat participated in procuring the taste by pressing a lever in response to a tone, however, those phasic taste responses vanished, phasic responses to the tone appearing instead. Our data provide strong evidence that the neural handling of taste is actually a distributed set of processes and that BLA is a nexus of these multiple processes. These results offer new insights into how amygdala imbues naturalistic sensory stimuli with value.

Key words: hedonics; sensory processing; single unit; multielectrode; electrophysiology; temporal coding

\section{Introduction}

The amygdala processes multiple attributes of sensory experiences simultaneously, including stimulus identity, emotional content (referred to as taste palatability), and reward value, by virtue of its connections with sensory cortex, orbitofrontal cortex, and the dopamine system (Berridge, 1996; Cardinal et al., 2002; Pare et al., 2002; O'Doherty, 2003; Saddoris et al., 2005). The involvement of the basolateral amygdalar nucleus (BLA) in these processes is suggested by electrophysiological and lesion experiments: BLA neurons respond in relation to a stimulus' sensory properties (Pare and Collins, 2000; Paton et al., 2006) as well as to its learned emotional and reward associations (Quirk et al., 1995; Schoenbaum et al., 1998, 1999; Repa et al., 2001), related but distinguishable properties that have been likened to "liking" and "wanting," respectively (Berridge, 1996). BLA damage, meanwhile, is associated with abnormal processing of sensory cues in disorders such as autism and Kluver-Bucy syndrome (Prather et al., 2001; Bauman and Kemper, 2003) and with impairments in the learning of new hedonic and reward-related responses to stimuli (Maren et al., 1996; LeDoux, 2000; Balleine et al., 2003; Schoenbaum et al., 2003; Maren and Quirk, 2004;

Received Aug. 15, 2008; revised Jan. 5, 2009; accepted Jan. 14, 2009.

This work was supported by National Institute on Deafness and Other Communication Disorders Grants DC008885 (A.F.), DC-006666 and DC-007703 (D.B.K.), and DC-008720 (S.E.G.). A.F. was also supported by the SloanSwartz Center for Theoretical Neuroscience at Brandeis University.

${ }^{*}$ A.F. and S.E.G. contributed equally to this work.

Correspondence should be addressed to Donald B. Katz, Volen National Center for Complex Systems, Brandeis University, MS 013, 415 South Street, Waltham, MA 02454. E-mail: dbkatz@brandeis.edu.

DOI:10.1523/JNEUROSCI.3898-08.2009

Copyright $\odot 2009$ Society for Neuroscience $\quad 0270-6474 / 09 / 292486-10 \$ 15.00 / 0$
Blankenship et al., 2005; Corbit and Balleine, 2005; Wang et al., 2006).

Taste stimuli, which are imbued with palatability and reward values, as well as with "pure" sensory properties, are excellent probes of amygdalar function. Both the central nucleus of the amygdala (Karimnamazi and Travers, 1998; Li et al., 2002; Huang et al., 2003; Lundy and Norgren, 2004; Tokita et al., 2004; Li et al., 2005) and BLA (Norgren, 1976; Veening, 1978; Bernard et al., 1993) receive taste input via reciprocal connections with gustatory brainstem, and BLA also receives taste feedback from cortex (Yamamoto et al., 1984; Bielavska and Roldan, 1996). Amygdala neurons are known to fire in response to taste administration (Scott et al., 1993; Nishijo et al., 1998, 2000; Grossman et al., 2008), and BLA lesions perturb both taste-related behaviors (Touzani et al., 1997; Ganaraja and Jeganathan, 2000) and taste learning (Gilbert et al., 2003; Reilly and Bornovalova, 2005; Touzani and Sclafani, 2005; Wang et al., 2006; St Andre and Reilly, 2007). Given the complexity of connectivity, it is reasonable to hypothesize that BLA taste responses should be rich and dynamic and that these dynamics should be related to those previously observed in gustatory cortex (GC), which processes first a taste's existence, then its identity, and then its palatability across the $2 \mathrm{~s}$ preceding swallowing (Katz et al., 2001a; Fontanini and Katz, 2006; Grossman et al., 2008). Presently, however, only the most general properties of amygdalar taste responses have been examined.

Here, we tested the above hypothesis in an analysis of awake rats' BLA taste responses. This analysis revealed two subgroups of BLA neurons that produce distinct taste responses. One taste neuron subtype did, in fact, reflect cooperation between amyg- 
dala and cortex for the purposes of processing palatability. The protracted dynamics of the taste responses in these neurons were strikingly similar to those produced by GC neurons (Katz et al., 2001a), differing only in the fact that that palatability-specific information vanished in BLA at the latency at which it has been shown to appear in cortex. We also observed a second, distinct subset of BLA taste neurons, however. These taste neurons showed three of the cardinal traits of neurons in the reward learning system (Schultz, 2001): they produced very brief, shortlatency responses to rewarding stimuli; these responses all but disappeared when the stimuli were self-administered; and in selfadministration trials, these neurons instead responded to a tone announcing that a lever press will cause taste delivery.

Our data provide strong evidence that the neural handling of taste is a distributed process and support previous studies suggesting a possible transmission of hedonic information from BLA to cortex (Escobar et al., 1998; Ferreira et al., 2005; Saddoris et al., 2005; Grossman et al., 2008). They offer new insights into how amygdala may imbue the coding of naturalistic sensory stimuli with value.

\section{Materials and Methods}

Subjects. Methods conformed to the Brandeis University Institutional Animal Care and Use Committee guidelines. Female Long-Evans rats ( $n=7 ; 250-300 \mathrm{~g}$ at time of surgery) served as subjects in this study. Animals were maintained on a $12 \mathrm{~h}$ light/dark schedule and were given $a d$ libitum access to chow and water, unless specified otherwise.

Surgery. Rats were anesthetized using an intraperitoneal injection of a ketamine/xylazine/acepromozine mixture $(100,5.2$, and $1 \mathrm{mg} / \mathrm{kg}$, respectively), with supplemental intraperitoneal injections administered as needed. Each anesthetized rat was placed in a standard stereotaxic device, where its scalp was excised, and holes were bored in its skull for the insertion of $0-80$ ground screws and electrode bundles. Multielectrode bundles ( 16 nichrome microwires attached to a microdrive) (Katz et al., $2001 \mathrm{~b}$ ) were inserted $0.5 \mathrm{~mm}$ above BLA (anteroposterior, -3 ; mediolateral, \pm 5.1 ; dorsoventral, -6.5 from dura). Once in place, the assemblies were cemented to the skull, along with two intraoral cannulae (IOC) (Fontanini and Katz, 2006), using dental acrylic. Rats were given $7 \mathrm{~d}$ to recover from the surgery.

Stimulus delivery protocol: passive and self-administrations. After recovery from surgery, rats were habituated to a $23.5 \mathrm{~h}$ water restriction paradigm to ensure adequate motivation to drink during the experimental procedures. Experimental sessions ensued only after rats had become adapted to restraint and administration of fluid through IOCs. In each adaptation session, the experimenter administered $40 \mu \mathrm{l}$ of water to the passive rat (these were referred to as "passive administrations") and also, on occasion, gave the rat the opportunity to press a lever located in front of the right forepaw for additional water deliveries (these were "selfadministrations"). For the latter, a $7 \mathrm{kHz}$ tone signaled water availability; the rat had $3 \mathrm{~s}$ after tone onset to lever press, at which time $40 \mu \mathrm{l}$ of water was delivered and the tone was interrupted. Lever presses in the absence of a tone went unrewarded. Within two to four sessions, rats learned to press once per tone and then to wait through the fore-period (and possible passive administration) for the next opportunity to self-administer.

Stimulus delivery sessions were similar to adaptation sessions, but 40 $\mu \mathrm{l}$ aliquots of (in mm) $100 \mathrm{NaCl}, 100$ sucrose, 100 citric acid, and 1 quinine $\mathrm{HCl}$ replaced water. Tastes were selected randomly without replacement, separately for passive and self-administrations. Within each session, passive and self-administrations were interleaved, with an average of $20 \mathrm{~s}$ between any two taste deliveries. Approximately $5 \mathrm{~s}$ after any taste delivery, rats received a $40 \mu \mathrm{l}$ aliquot of water as a rinse. Sessions lasted until rats became inattentive or satiated, typically 60-90 min (Fontanini and Katz, 2005, 2006; de Araujo et al., 2006), for a total of 14-20 trials of each taste per session. Occasionally, sessions were truncated because of inattention; neural responses obtained during these sessions were included in the population analysis of taste response properties (see
Fig. 2) but were excluded in more fine-grained analyses of individual response dynamics.

Electrophysiology. Recordings were amplified (1000-2000), filtered $(300-800 \mathrm{~Hz})$, and digitized. Single neurons of a $>3: 1$ signal-to-noise ratio were isolated by using a waveform template, augmented with offline cluster cutting software (Plexon).

Analysis of taste profiles. Several analytic methods were used to characterize BLA neuron responses. A neuron was initially deemed a taste neuron if its firing rate in response to at least one taste (averaged over the first $2.5 \mathrm{~s}$ ) was different than to others. The significance of the difference was established by using the main effect for taste in a two-way, mixed-effect ANOVA (taste [sucrose, $\mathrm{NaCl}$, citric acid, quinine] $\times$ time [successive $250 \mathrm{~ms}$ bins of firing rate]). This is a relatively conservative measurement: a neuron producing strong but similar responses to all tastes will not be deemed taste responsive by this analysis.

The interaction term of this two-way ANOVA allowed us to more closely examine the taste response profile for each neuron. A $p$ value of $<0.05$ on the interaction term reveals that the time course of response to at least one taste was significantly different from that to other tastes (i.e., that there is taste-related information in the temporal codes). Given the relatively low firing rates produced by BLA neurons, inhibitory neurons were difficult to evaluate and were thus excluded from most analyses.

Additional simple calculations extended our analysis of "taste specificity" in BLA neurons. First, for each $250 \mathrm{~ms}$ postadministration bin, we calculated the linear difference between the responses (spikes per seconds) to each pair of tastes; the across-pair average provided a basic estimate of how distinctly that particular neuron responded to each taste at that particular poststimulus time. We then extended this analysis to provide a basic estimate of the palatability-specific information provided by the neurons, separating the average differences into those between pairs of tastes with similar palatabilities (sucrose $/ \mathrm{NaCl}$, acid/quinine) and those between pairs with dissimilar palatabilities (sucrose/quinine, $\mathrm{NaCl}$ /quinine, sucrose/acid, $\mathrm{NaCl} /$ acid). If the latter average was significantly higher than the former, then the neurons fired more similarly to tastes with similar palatabilities (i.e., they fired in a palatability-specific manner).

Finally, we compared the response of each neuron in a particular 250 $\mathrm{ms}$ bin to prestimulus baseline activity, to determine which tastes caused significant modulations at that time. A third measure of taste specificity, and an initial measure of the duration of particular responses, was the tendency of a neuron to respond to only a subset of the taste stimuli at that particular time.

Analysis of response latencies and durations. To determine the onset and duration of significant fluctuations in firing rate with greater temporal precision than afforded by $250 \mathrm{~ms}$ bins, a moving-window analysis was used on across-trial response summations (Katz et al., 2001a). Firing rates were calculated for each movement of the window, and $99 \%$ confidence intervals were calculated on the basis of prestimulus firing. When firing was determined to fall outside the confidence interval for multiple (more than three) consecutive windows, the first such window was determined to be the time of response onset; the response duration was the amount of time between the onset and the end of the last significant window.

Moving-window analyses can cause artifactual response smoothing; sudden changes in firing rate are "distributed" across time by the window. To minimize this potential problem in our estimates of onset and duration, our analysis differed from a standard moving-window analysis in three ways. First, rather than using a peristimulus time histogram (PSTH), a cumulative firing plot [cumulative sum (cusum)] was used; this allowed us to include each action potential separately. Second, the size of the window was set to be a specific percentage (5\%) of the spikes in the cusum, rather than a specific number of milliseconds; thus the window would "shrink" around sudden firing rate increases. Finally, because a cusum plot travels diagonally up and to the right [the axes of such a plot are time and spike number (from first to last)], our analysis was technically not of firing rates themselves, but of slopes in the cusum line.

Classification of BLA responses. A classification algorithm was used to determine whether neural responses in the middle epoch would process palatability (Jones et al., 2007). Briefly, population PSTHs (bin size, 250 
$\mathrm{ms}$ ) were computed for all the neurons showing protracted responses by iteratively averaging for each taste in all the trials but one. Single trials were then classified, and a confusion matrix was compiled on the basis of their Euclidean distance from the population PSTH. To determine the average performance in the middle epoch, the classification results for the bins between 250 and $1250 \mathrm{~ms}$ after stimulus were averaged.

Analysis of BLA neuron subtypes. K-mean clustering was applied to response latency and duration data, to determine whether neurons clustered into subtypes. To further confirm the separation of these clusters, neuronal groups suggested via k-mean clustering were subjected to additional $t$ tests comparing their onset and duration values. A series of additional statistical analyses were performed on the separated neuronal groups to examine differences and similarities in their taste response profiles. Twoway, repeated-measure ANOVAs were performed on each group separately using time (firing rates during consecutive $250 \mathrm{~ms}$ bins) and taste (response to four tastes) as withinand between-subject factors, respectively. Post hoc tests supported and further explained these analyses.

Histology. After the experimental sessions, subjects were deeply anesthetized and perfused

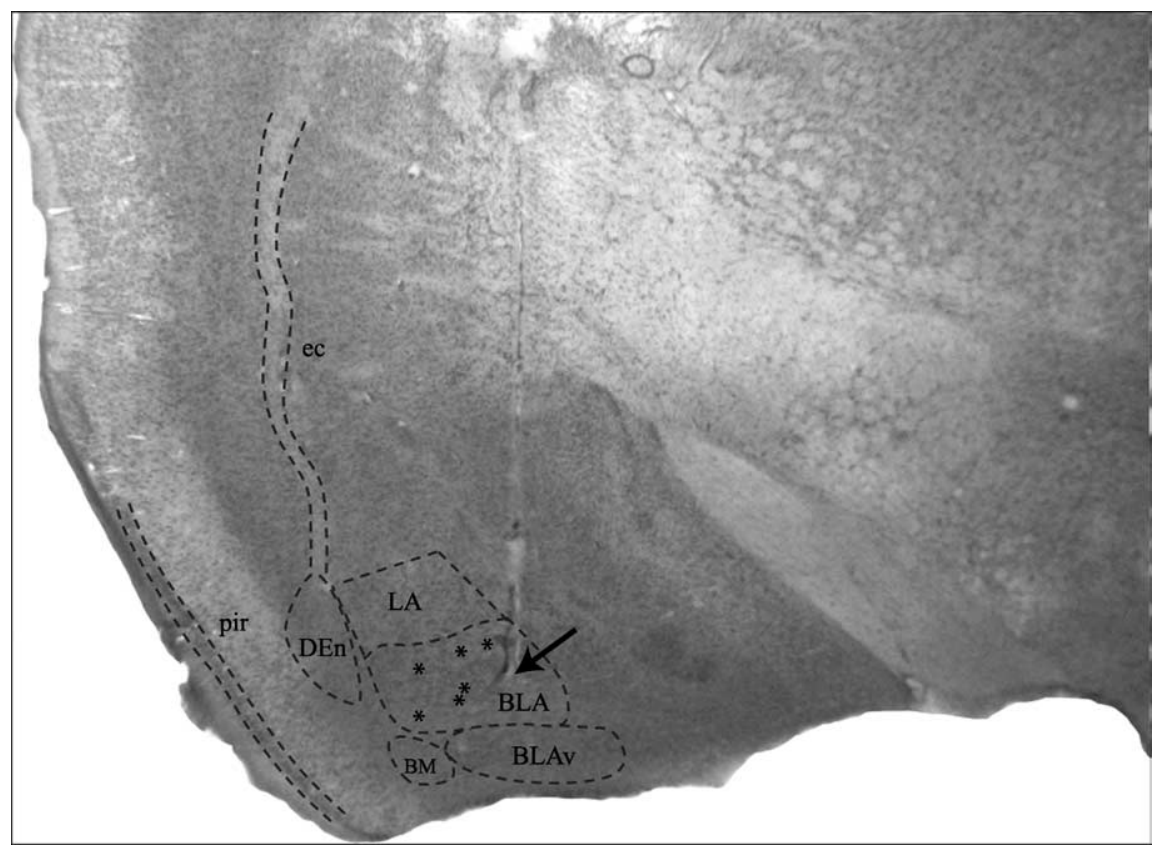

Figure 1. Electrode placement. A sample histology shows placement of the electrode tips. The cannula track is visible extending ventrally from the surface and terminating in the basolateral amygdala. The lesion hole is marked with a black arrow. Asterisks denote the locations of the recording tips for the remaining rats. BLAv, Ventral basolateral amygdala; BM, basomedial amygdala; DEn, dorsal endopiriform nucleus; ec, external capsule; LA, lateral amygdala; pir, piriform cortex. through the heart with saline, followed by $10 \%$ formalin in saline. Seven seconds of DC $(7 \mu \mathrm{A})$ were passed through selected microwires in preparation for staining. Brains were removed and immersed in a sucrose formalin mixture, where they remained, refrigerated, until fixed. Sections $(40 \mu \mathrm{m})$ cut through BLA on a freezing microtome were stained with cresyl violet for cell bodies. Only data from animals with electrodes placed within the confines of BLA were included in the analyses.

\section{Results}

\section{Two subtypes of taste-specific responses in BLA}

Figure 1, a representative photomicrograph, reveals the electrode cannula track and location of one set of electrode tips situated in BLA (Paxinos and Watson, 1997); overlain on this image are the locations of the other bundle tips. A total of 96 BLA neurons were collected from chronically indwelling electrode bundles in seven rats (22 sessions in all; $4.4 \pm 2.1$ neurons/session). Of these, 75 were held across multiple (more than seven) applications of the full array of four tastes, and of these, 21 (28\% of the total sample) responded with taste-specific average firing rates $(p<0.05$ for the main effect of taste in a two-way [taste $\times$ time] ANOVA). The interaction terms of the same ANOVAs revealed an additional nine ( $12 \%$ of the total sample) BLA neurons that produced responses with different time courses to different tastes. Overall, 25 neurons ( $33 \%$ of the total BLA sample) were taste specific according to rate, time course, or some combination of the two. This represents a much higher percentage than that previously reported for monkeys (Scott et al., 1993) and rats (Nishijo et al., 1998), a fact attributable to our consideration of time course and to the delivery of multiple trials of each taste (which added statistical power to our analysis).

We also examined the time courses of BLA taste responses, calculating the onset times and durations of firing rate changes (compared with baseline firing) using a moving-window analysis. In the entire sample, 65 significant elevations from baseline were observed in 28 neurons (this number is slightly different

from those described above because the moving-window analysis compares individual responses to prestimulus baselines, whereas the two-way ANOVA compares responses between taste, and because the moving-window analysis is more conservative with regard to detecting inhibitory responses). The vast majority (85.5\%) of these modulations had latencies of $<250 \mathrm{~ms}$ (mean, $86.6 \pm 12.2 \mathrm{~ms}$ ), but response durations varied widely, from $<100 \mathrm{~ms}$ to well over $1 \mathrm{~s}$.

When average response latencies and durations were plotted against one another, it became clear that taste-responsive BLA neurons fell naturally into two categories, one of short-latency, long-duration (LD) responses, and another of even shorterlatency, short-duration (SD) responses (Fig. $2 \mathrm{~A}$ ). Cluster analysis confirmed this separation (Fig. 2B). For convenience, we refer to these subgroupings as LD and SD neurons, respectively. The two clusters did not differ in either anatomical localization or waveform shape (data not shown), but they differed significantly along both dimensions of Figure $2 A$; SD neuron responses were of shorter average duration than those of LD neurons ( $144 \pm 28$ vs $1388 \pm 71 \mathrm{~ms}$, respectively; $\left.t_{(22)}=19.9 ; p<0.001\right)$ and were also of shorter average latency than LD neurons (61 \pm 9 vs $130 \pm 25$ $\mathrm{ms}$, respectively; $t_{(22)}=3.29 ; p<0.01$ ).

To simplify further analysis of the neurons that were tested with all four tastes, responses were collapsed into $250 \mathrm{~ms}$ bins (results were similar using 50, 100, or $200 \mathrm{~ms}$ bins, however). Figure $2 C$ shows the general time courses of taste responses in $\mathrm{SD}$ (red trace) and LD (green trace) neurons, averaged across taste. During the first $250 \mathrm{~ms}$ bin, the two types of neurons responded strongly and similarly, but afterward the responses were quite different: $S D$ responses remained elevated above baseline for only the first $250 \mathrm{~ms}$ ( $t$ tests comparing bin 1 to other bins; all $p<$ 0.001 ), whereas LD responses declined much more slowly. A twoway, repeated-measures ANOVA of these data revealed that SD and LD responses had significantly different time courses (interaction; $\left.F_{(54,1)}=7.17 ; p<.001\right)$. Post hoc tests demonstrated that 
A
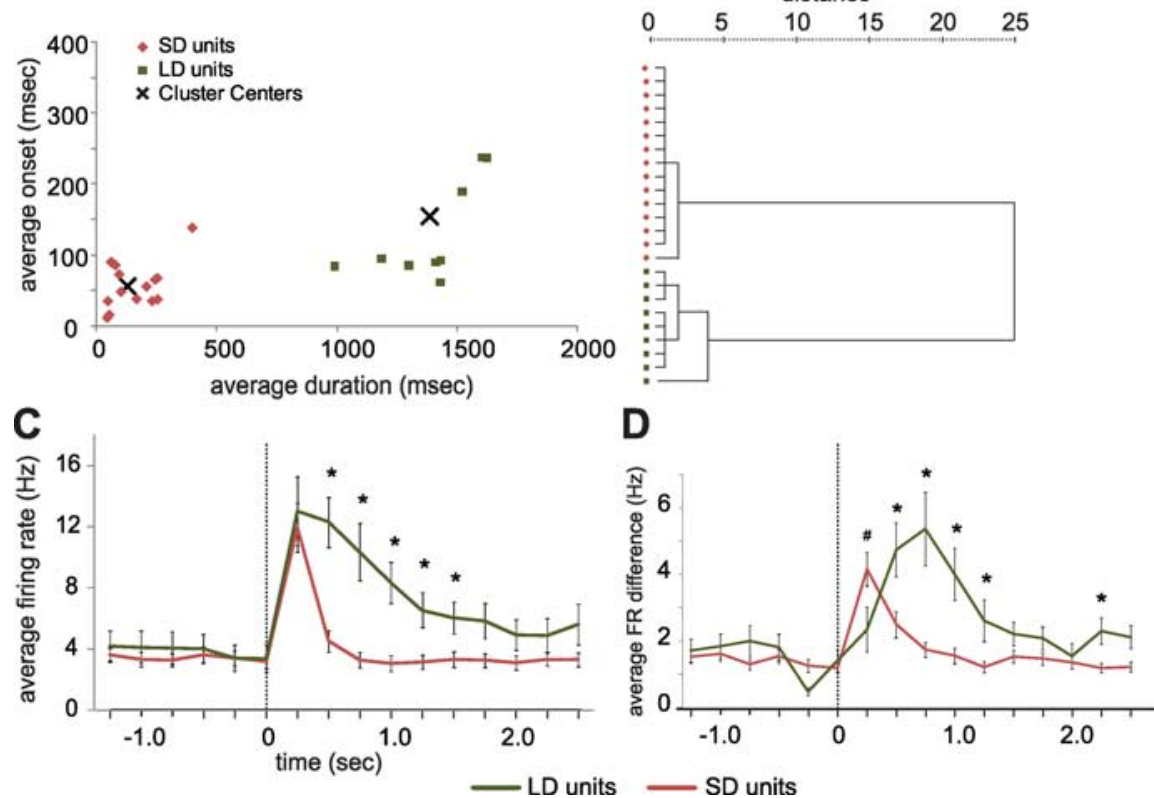

Figure 2. Two types of taste neurons can be observed in BLA. $A$, Scatterplot showing the response properties of all BLA neurons that responded to taste administration with excitatory changes in firing rate. Each neuron's responses were averaged across tastes ( $x$-axis, average response duration; $y$-axis, average response onset), such that there is one dot on the graph per neuron. Neurons that appear to cluster together are plotted in the same color. $\boldsymbol{B}$, The results of a hierarchical cluster analysis on the same data, confirming that BLA taste-responsive neurons, color-coded to match $\boldsymbol{A}$, come in two types. Note the high intracluster similarity (far-left branching) and low between-cluster similarity. C, Population histograms of the neurons in each cluster, color-coded to match $\boldsymbol{A}$ and $\boldsymbol{B}$, showing that the responses of LD and SD neurons start at similar magnitudes but quickly diverge. The $x$-axis is time after delivery (the time of taste delivery is noted with a vertical line), and the $y$-axis is average firing rate in spikes per second. Error bars (here and in all other figures) are SEM. D, Plot showing, for LD and SD neurons, the average between-taste differences in response. The $x$-axis is time after delivery, and the $y$-axis is difference in spikes per second. SD responses to different tastes differ immediately, whereas $L D$ responses to different tastes are similar early and then diverge. ${ }^{*} p<0.05, \mathrm{LD}>\mathrm{SD} ;{ }^{\#} p<0.05, \mathrm{SD}>\mathrm{LD}$.

SD and LD firing rates were different from 0.25 to $1.75 \mathrm{~s}$ after taste administration.

\section{LD neurons convey palatability-related information in the middle of three response epochs}

In addition to differing in time course, $\mathrm{SD}$ and $\mathrm{LD}$ responses also differed in information content. An initial appreciation of this fact can be gained by looking at a simple measure of taste specificity, the average difference between responses to pairs of tastes (Fig. 2D); in this analysis, neurons that respond identically to any pair of tastes (i.e., fire the same number of spikes per second to all tastes) show a difference of 0 for those two tastes in that time bin.

This analysis revealed the brief SD responses to be taste specific (although it does not reveal precisely which pairs of tastes contribute to that taste specificity; that issue will be taken up below), in that the differences between responses to the different stimuli were significantly larger than those observed during prestimulus periods $\left(t_{(59)}=5.01 ; p<0.001\right)$. In fact, SD neurons responded more taste-distinctively than $\mathrm{LD}$ neurons during the first $250 \mathrm{~ms}$ bin of the taste responses; during this same period, the LD responses were not taste specific at all $(p>0.2)$, despite the fact that their absolute firing rates peaked during this bin (Fig. $2 C)$. LD neurons responded in a more taste-specific manner than SD neurons in each of the next four bins, however (all $p<0.05$ ), across a period in which the overall response amplitudes steadily declined. LD responses remained significantly taste specific $(p<$ 0.01 ) for a relatively long time after taste administration. A twoway ANOVA (time by neuron type) revealed the difference be- tween the patterns of SD and LD taste specificity to be significant (interaction; $\left.F_{(9,1)}=7.73 ; p<0.001\right)$.

We predicted that the protracted LD neuron responses would progress through a series of three processing epochs, each containing distinct types of information, in reflection of cooperative coding between BLA and GC. Our analysis supported this prediction. The time structure of BLA taste responses could be observed by eye (Fig. $3 A$; shading denotes significantly elevated firing): LD neurons responded first to all tastes (we called this period epoch 1) and then to a subset of tastes (in this case, $\mathrm{NaCl}$ and sucrose; epoch 2); after epoch 2, LD neurons typically responded to only one taste at any particular time (here, the response was to sucrose at one point and to $\mathrm{NaCl}$ at another point); this was called epoch 3. Population analysis (Fig. 3B) bore out these trends: LD neurons responded to all four tastes during the first $250 \mathrm{~ms}$ poststimulus bin; this generality of response faded quickly, however, and vanished completely before $0.5-0.75$ s of poststimulus time had elapsed. During the period of $0.25-1.0 \mathrm{~s}$ after delivery, LD neurons instead responded to two to three tastes (Fig. 3B, red line). After $1.0 \mathrm{~s}$ postdelivery, they responded to only one taste (Fig. 3B, blue line). In both the number of response epochs and the timing of epoch transitions, LD responses matched well with GC responses (Katz et al., 2001a).

Because the amygdala is known to be a primary processor of taste palatability, we tested the hypothesis that LD neurons, specifically the second epoch, in which they responded to either two or three tastes, provide palatability-related information. The term "palatability" is widely regarded to refer to how likeable and pleasing a taste is (Breslin et al., 1992; Berridge, 2000); for this analysis, we made use of the fact that the rat finds sucrose and $\mathrm{NaCl}$ pleasing and finds quinine and citric acid aversive, a fact evident in the palatability-specific faces that a rat makes when these tastes are on its tongue (Fig. 4A) (Grill and Norgren, 1978; Breslin et al., 1992; Fontanini and Katz, 2006; Caras et al., 2008).

Figure $4 B$ shows which tastes LD neurons responded to in epoch 2. Most notable is what was absent: not one single neuron responded to both sucrose and quinine, the two extremes of the palatability continuum. In fact, the bulk $(60 \%)$ of responses in the period between 0.25 and $1.0 \mathrm{~s}$ after taste delivery were restricted to palatabilityspecific pairs of tastes; the percentage was even higher $(86 \%)$ when analysis was restricted to bins in which neurons responded to two tastes alone. More LD neurons responded to the aversive tastes than to the palatable tastes, a finding that accords well with previous work (Zald et al., 1998; Oya et al., 2002).

$\mathrm{NaCl}$ and sucrose behaved similarly in the vast majority (80\%) of these cases: both caused responses in $40 \%$ of the bins, and both were ineffective in $40 \%$ (the exceptions were the NCQ and NQ bins). $\mathrm{N}$ behaved like $\mathrm{C}$ and Q, meanwhile, in only 30 and $20 \%$ of the bins, respectively. Analogously, aversive Q behaved more like 
A

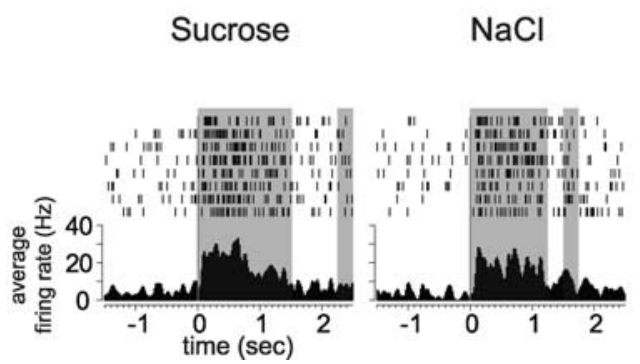

Citric Acid

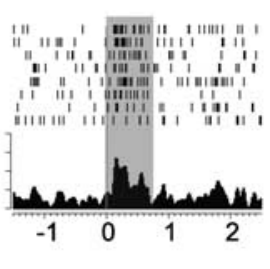

B

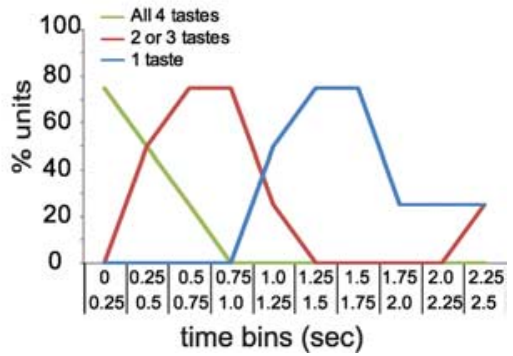

Figure 3. LD neurons produce time-varying taste responses with dynamics similar to those of $G C$. $A$, The top halves of each panel are the spiking activity of a representative $L D$ neuron in response to each of the four tastes. Each row is a single trial, and each hash mark is an action potential; the $x$-axis is time, with 0 being the moment of taste delivery (marked with a vertical line). These plots are summarized below in PSTHs, which show the firing rate (in spikes per second) of the neuron in response to the tastes. Shaded areas indicate periods of firing significantly higher than the prestimulus rate. Note that there is an initial excitatory response to each taste but that the quinine and citric acid responses return quickly to baseline; the sucrose and NaCl responses remain high throughout the first second of the response, and the sucrose response remains high even after the $\mathrm{NaCl}$ response has declined. $\boldsymbol{B}$, Plot showing the percentage of $L D$ neurons ( $y$-axis) that responded to one (blue line), two to three (red line), or all four (green line) tastes in each $250 \mathrm{~ms}$ bin of poststimulus time ( $x$-axis). Each category peaks during a distinct epoch of time (neurons are most likely to respond to all 4 tastes early, to $2-3$ tastes later, and to 1 taste later still).

A

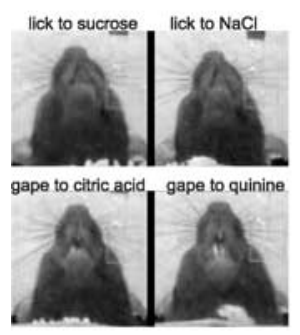

B
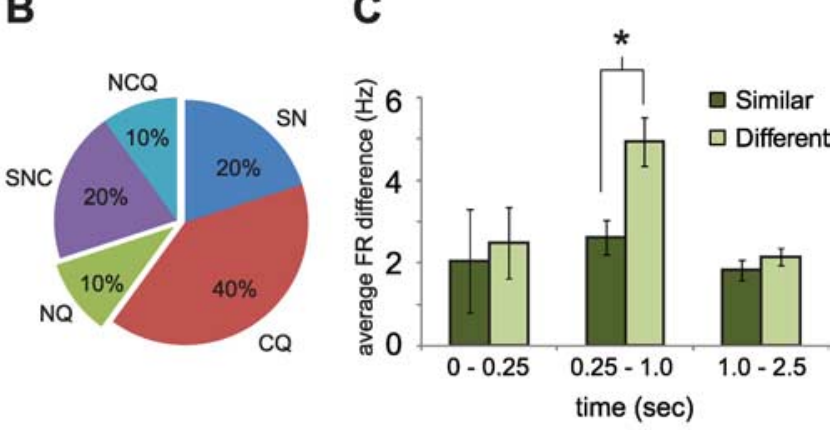

D

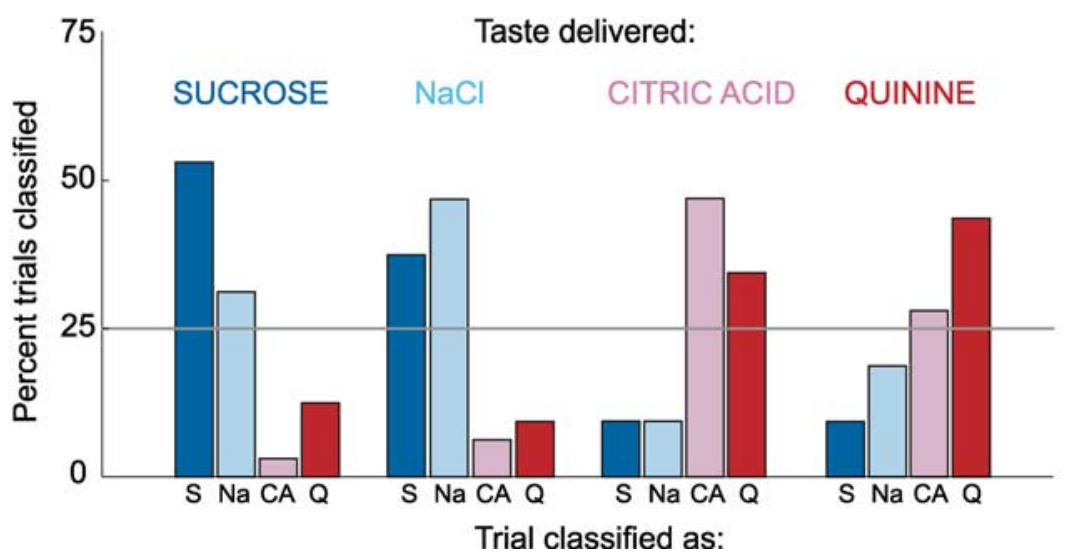

Figure 4. LD neurons carry palatability-related information in the middle portion of their temporal codes. $A$, Photographs displaying the stereotyped orofacial reactions to the delivery of a palatable (top; licking to sucrose and $\mathrm{NaCl}$ ) and unpalatable (bottom; gaping to citric acid and quinine) taste delivery. These responses reveal the perceived palatability of the taste qualities delivered. $\boldsymbol{B}$, Breakdown of what tastes caused responses during time bins in which neurons responded to two to three tastes. $S$, Sucrose; $\mathrm{N}, \mathrm{NaCl} ; \mathrm{C}$, citric acid; $\mathrm{Q}$, quinine. Sixty percent of the two to three taste responses were to either $\mathrm{S} / \mathrm{N}$ (i.e., the pair of palatable tastes) or C/Q (i.e., the pair of unpalatable tastes). That is, with few exceptions (an occasional bin with responses to N/Q), LD neurons responded to tastes with similar palatabilities. $\boldsymbol{C}$, This graph shows, for each epoch implied in $\boldsymbol{A}$, the difference (in spikes per second; $y$-axis) between responses to tastes with similar palatabilities (dark green bars) and different palatabilities (light green bars). During the middle epoch of the response only (the epoch dominated by responses to pairs of tastes), there was much more difference between responses to tastes with different palatabilities $\left({ }^{*} p<0.01\right)$. FR, Firing rate. $\boldsymbol{D}$, Template-based classification of $L D$ epoch 2 taste responses shows the actual taste delivered was identifiable ( $y$-axis, percentage correct; $x$-axis, classification of taste trial) at twice chance (horizontal dashed line) rates. The greatest percentage of errors, consistent across all tastes, was the result of "palatability confusion" (sucrose and NaCl were most often confused for one another, as were citric acid and quinine). For ease of visualization, palatable tastes are in light and dark blue, whereas unpalatable tastes are in light and dark red.

aversive $\mathrm{C}$ (70\% of bins) than it did like either $\mathrm{N}$ or $\mathrm{S}$ (20 and $0 \%$, respectively).

Figure $4 C$ reveals the general impact that this pattern of responses had on palatability specificity in LD responses, showing average between-taste differences for tastes with similar palatabilities (sucrose/ $\mathrm{NaCl}$, quinine/acid) or distinct palatabilities during each epoch of the responses: the first $250 \mathrm{~ms}$ of the response (i.e., the period when most neurons responded to all four tastes), the period between 0.25 and $1.0 \mathrm{~s}$ after taste delivery (when most neurons responded to either two or three tastes), and later time points. For both the first and third epochs of the responses, the differences between palatability-specific pairs were similar to those between pairs with distinct palatabilities. During epoch 2 , however, there was significantly less difference between sucrose and $\mathrm{NaCl}$ (and between quinine and citric acid) than between other taste pairs $\left(t_{(96)}=2.69 ; p<\right.$ $0.01)$. Although a low but significant $\left(t_{(22)}\right.$ $=2.07 ; p<0.05$ ) level of palatability specificity could be detected in epoch 3 in an analysis that collapsed across bins (data not shown), the vast majority of palatability-related LD response information lives in epoch 2.

These results suggest that it should be harder to tell LD responses induced by $\mathrm{NaCl}$ from those induced by sucrose than from those induced by quinine and citric acid. To test this prediction, we built "templates" of the epoch 2 population responses to each taste and used those templates to classify the individual trials. The results of this analysis (Fig. 4D) shows both how reliably well defined (i.e., taste specific) each neural response was and also reveals which tastes were most often confused for each other. Each taste was cor- 
A
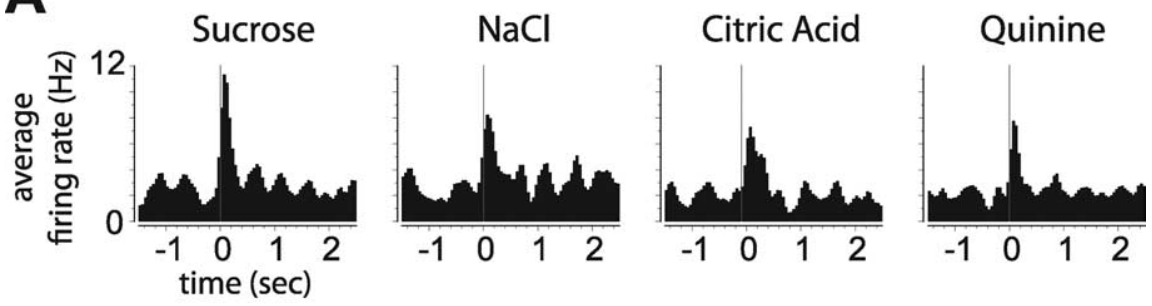

B

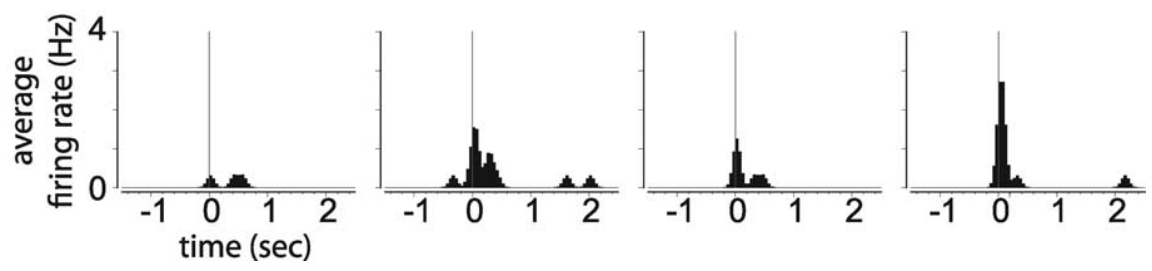

Figure 5. SD responses code reward value. $\boldsymbol{A}, \mathrm{PSTH}$ s of representative SD responses to all four tastes. Each response is similarly phasic, but the sucrose response is largest, and the quinine response is smallest. Time of taste delivery is marked with a vertical line. $\boldsymbol{B}$, Another SD neuron (with a just barely $>0$ baseline firing rate), which responded most strongly to quinine and least strongly to sucrose.

rectly identified at approximately twice the rate that one would expect by chance (chance is $25 \%$ ). Furthermore, for each taste, the most common error made by the classifier algorithm was to misidentify the trial as coming from the other taste with the same palatability $(32.8 \%$ of the trials were within-palatability confusions, whereas only $9.7 \%$ were opposite-palatability confusions). This pattern of confusion confirms that LD responses serve as good predictors of stimulus palatability.

\section{SD neurons reflect rewarding taste properties during surprise deliveries}

As already noted (Fig. 2D), taste-related information is available in BLA within $60 \mathrm{~ms}$ of taste delivery, via the responses of SD neurons. This response latency is much smaller than that observed in GC and, in fact, is unlike that of any taste responses of which we are aware (Katz et al., 2001a; Fontanini and Katz, 2006) (but see Stapleton et al., 2006; Grossman et al., 2008). What these responses do resemble, in their latency and brevity, are reward responses. Neurons within the reward system, including both dopamine neurons in the midbrain and their amygdalar targets, respond to the presentation of rewarding stimuli with phasic bursts of action potentials that strongly resemble those produced by SD neurons in response to tastes (Mirenowicz and Schultz, 1996; Pratt and Mizumori, 1998; Schultz, 2001; Paton et al., 2006; Roesch et al., 2007; Tye and Janak, 2007).

One reasonable hypothesis as to the nature of SD neurons is therefore related to BLA's known involvement in reward, in determining what stimuli an animal will work to receive or avoid. Midbrain dopamine neurons typically respond more vigorously to appetitive stimuli than to punishing stimuli (Mirenowicz and Schultz, 1996; Pan et al., 2005; Roesch et al., 2007), and BLA contains both neurons that respond to positive rewards and those that respond to punishment (Schoenbaum et al., 1999; Paton et al., 2006; Belova et al., 2007); furthermore, a subset of neurons in both locations have been shown to respond to rewards of either valence (sometimes called "nonvalenced" neurons) [Belova et al. (2007), their Fig. 2]. So it was in the majority of our SD neuron sample: 4 of $10 \mathrm{SD}$ neurons responded most strongly to sucrose, which is, by far, the most rewarding of our four tastes $(\mathrm{NaCl}$ is palatable but not particularly rewarding) (Berridge and Schulkin, 1989), and least to quinine (the uniquely punishing taste in our array) (Fig. 5A), or else most strongly to quinine and least strongly to sucrose (Fig. 5B); these patterns occurred more than twice as often as would be expected by chance, assuming equal probability of each pattern $(16.7 \%)$. Furthermore, five of the remaining SD neurons responded to both sucrose and quinine with similar bursts of moderate magnitude.

We confirmed that SD neurons did not, as a group, provide information on taste palatability, analyzing response differences for similar and dissimilar taste pairs as was done for LD neurons. SD responses to taste pairs with similar palatability (e.g., sucrose and $\mathrm{NaCl}$ ) were not significantly more similar than responses to taste pairs with divergent palatability (e.g., sucrose and quinine). The average firing rate difference for similar taste pairs was $7.4 \pm 1.8$ spikes/s, whereas the average firing rate difference for dissimilar taste pairs was $8.8 \pm 1.6$ spikes $/ \mathrm{s}\left(t_{(58)}=\right.$ $2.00 ; p>0.5)$.

Previous results from human and nonhuman primates suggest that dopamine reward responses, both amygdalar and midbrain, are strongest when the reward, positive or negative, is unanticipated (Schultz et al., 1997; Belova et al., 2007; Roesch et al., 2007; Kufahl et al., 2008), much like behavioral “ $\alpha$ ” responses to strong, unexpected stimuli (Gruart et al., 2000). When rewards are expected, reward responses shift from the rewarding stimulus itself to the stimulus triggering that expectation (Schultz, 2001). We therefore analyzed the trials in which the rats initiated delivery of a randomly selected taste by pressing a lever (these trials were pseudorandomly interspersed among the experimenterinitiated deliveries). Although our rats could not learn to predict which taste would arrive after each lever press, they clearly learned to press a lever to receive tastes, and thus to expect taste delivery (delivery that, perhaps because of water restriction, carries a basal reward value). We reasoned that any BLA reward $/ \alpha$ responses would be uniquely sensitive to the difference between and passive delivery and self-administration and therefore predicted (1) that SD taste responses would vanish during selfadministration and (2) that these same neurons would show strong, sharp tone responses.

In fact, SD taste responses were almost completely blocked by this manipulation of taste delivery. A full $60 \%$ of the SD neurons identified in experimenter-initiated trials responded significantly differently in self-administration trials; in $66.7 \%$ of these neurons, this was true for every taste response. Furthermore, the entirety of the changes in SD taste coding wrought by selfadministration consisted of response diminutions or outright response eliminations, such that the average magnitude of an SD response was significantly smaller (reduced by $>75 \%$ ) in selfadministration trials (Fig. 6A), according to two-way ANOVA (time poststimulus $\times$ delivery condition; $F_{\text {condition(9,1) }}=8.8, p<$ $\left.0.01 ; F_{\text {interaction(9,1) }}=25.6 ; p<0.001\right)$. Only insignificant elevations of SD neuron activity were observed in anticipation of taste delivery, but self-administration nearly abolished taste responses themselves.

Figure $6 B$ shows that the opposite was true for LD neurons. 
A
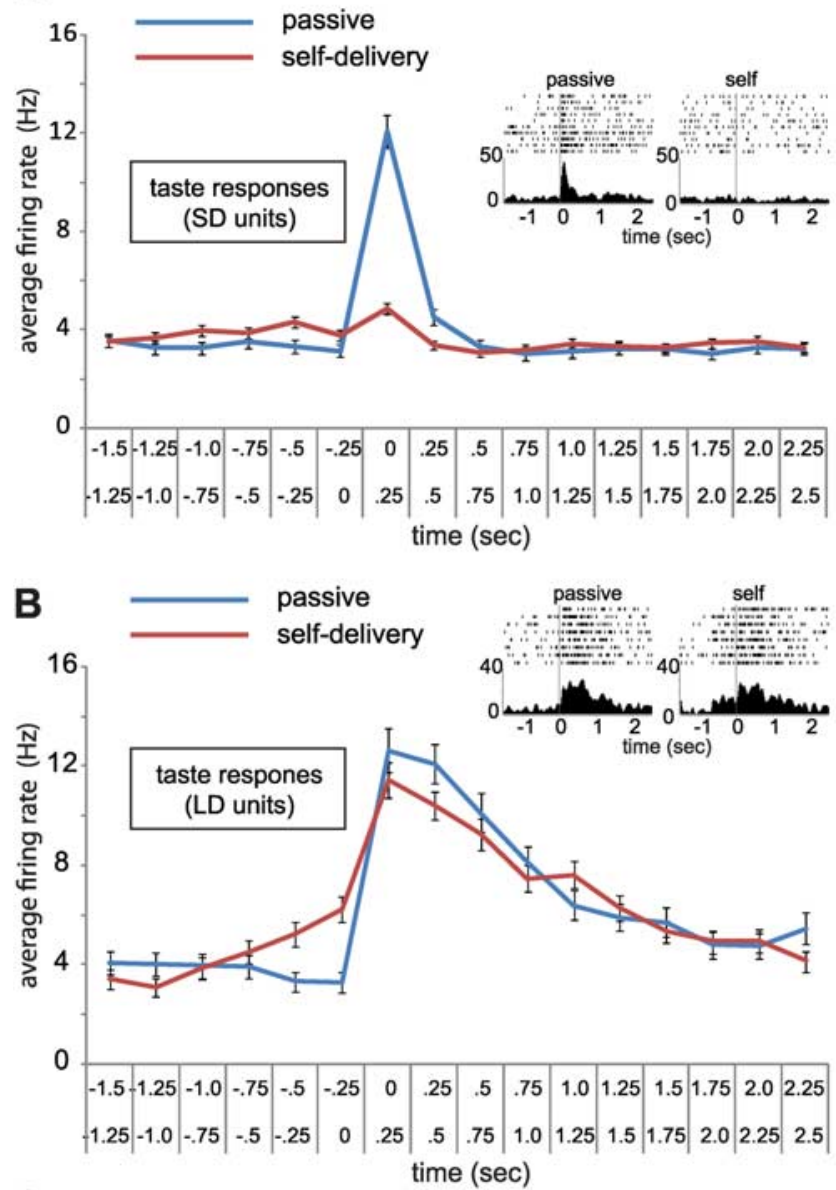

C

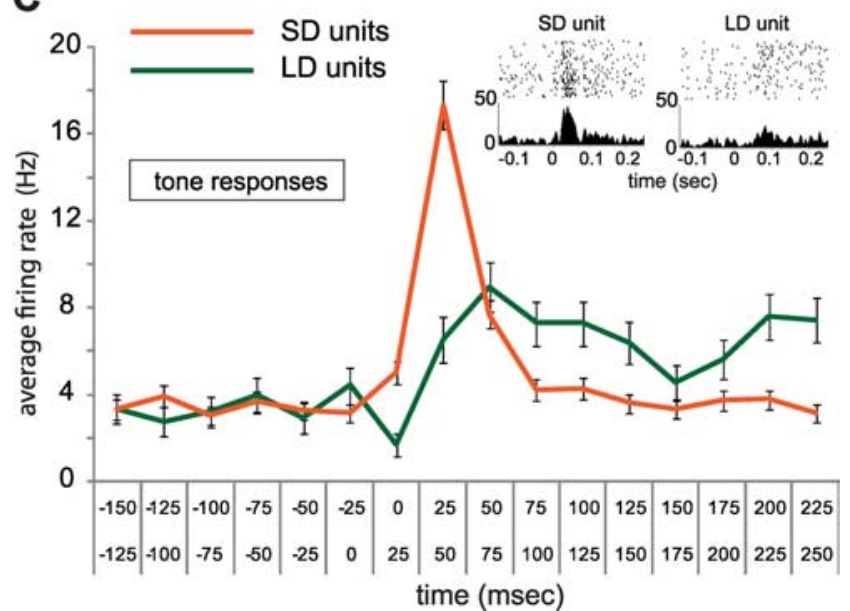

Figure 6. Self-administration affects $S D$ responses but not $L D$ responses. $A$, The blue line, essentially replicated from Figure $2 C$, is the population histogram ( $x$-axis, time after delivery in seconds; $y$-axis, firing rate in spikes per second) for SD neurons in response to taste stimuli. The red line shows the population histogram for the same neurons during self-administration of the same tastes. Selfadministration had little impact on activity before taste delivery and all but eliminated the taste responses themselves. The insets show an example of a single SD response to experimenteradministrated (left) and self-administrated (right) sucrose ( $x$-axis, time in seconds; $y$-axis, firing rate in spikes per second). Time of taste delivery is marked with a vertical line. $\boldsymbol{B}$, Similar population histograms (blue line, experimenter administration; red line, self-administration) for LD neurons. There was no difference in the taste responses themselves, but a significant anticipatory response preceded self-administration. The insets show representative example responses. See Results for statistical details. C, Population histogram for all LD (green line) and SD (orange line) units in the time period immediately surrounding tone onset before self-administration. $x$-axis, Time in milliseconds; $y$-axis, firing rate in spikes per second. SD units show fast, phasic response to tone peaking between 25 and 50 ms. LD units show more gradual, lower-amplitude tone responses.
Whereas anticipation of self-administration caused significant elevations of prestimulus $\mathrm{LD}$ firing rates in the $250 \mathrm{~ms}$ immediately preceding stimulus delivery $\left(t_{(30)}=2.38 ; p<0.05\right)$, the LD taste responses themselves were unchanged by self-administration $\left(F_{\text {interaction }(9,1)}=1.54 ; p>0.1\right)$. Self-administration changed only $12 \%$ of the bins in which $\mathrm{LD}$ neurons responded to tastes, the majority (57\%) of which were found in the first $250 \mathrm{~ms}$ of the responses.

This blocking of taste response was unlikely a direct cause of motor inhibition. Rats were well trained, typically pressing only once after hearing the tone (average number of presses in the $2.5 \mathrm{~s}$ after the first lever press was $0.069 \pm 0.055$ ). It is unlikely that any residual movement (end of lever release) could have caused activity that blocked the taste responses, and the latency of the next lever press within the $2.5 \mathrm{~s}$ after taste was $1.42 \pm 0.46 \mathrm{~s}$. Furthermore, not only did lever pressing have no effect on LD taste responses, it also failed to inhibit the activity preparatory to $\mathrm{LD}$ responses.

Self-administration trials were preceded by a tone that announced taste availability. SD neurons specifically responded to that tone in self-administration trials with short-latency phasic increases in firing (Fig. $6 \mathrm{C}$ ), just as reward neurons in the dopamine system have been shown to do (Schultz, 2001). The population average and representative example (Fig. $6 C$, inset) show these to be classic examples of auditory responses (phasic and sharply time-locked to tone onset); because each consisted of one or a few spikes per trial and the rats' reaction times to the tone varied widely (average $\pm S D, 684 \pm 258 \mathrm{~ms}$ ), these tone responses had no noticeable impact on PSTHs keyed to taste delivery (Fig. $6 A)$. LD neurons, meanwhile, responded only slightly and gradually to the tone, despite showing strong anticipatory firing leading up to taste delivery (Fig. $6 B$ ). SD tone responses were significantly stronger than $\mathrm{LD}$ tone responses $\left(t_{(966)}=1.96 ; p<0.001\right)$.

In summary, SD neuron taste responses were strongly affected by stimulus self-administration, and LD neuron taste responses were not $\left(F_{\text {interaction }(9,1)}=7.19 ; p<0.001\right)$. Given the similarity between these neurons' responses and those noted in work on amygdalar reward coding (Schoenbaum et al., 1999; Belova et al., 2007; Kufahl et al., 2008) (their brevity, their short latencies, their patterns of taste and tone responses, and their sensitivity to expectation), we argue that SD neurons are likely involved in the coding of stimulus reward value (while recognizing that they may also be involved in the coding of palatability or motor variables; see Discussion).

\section{Discussion}

The two subtypes of BLA taste neurons described here were dissociated, without prior prejudice, on the basis of response duration: one (LD neurons) produces taste responses that last longer than $1 \mathrm{~s}$, on average; the other (SD neurons), meanwhile, responds to each taste phasically (durations $\sim 200 \mathrm{~ms}$ ).

The differences between LD and SD neurons go far beyond duration, however. Taste specificity is lacking in the first $250 \mathrm{~ms}$ of $\mathrm{LD}$ responses, whereas $\mathrm{SD}$ responses are taste specific within $\sim 60 \mathrm{~ms}$ of stimulus onset. Taste specificity in LD neurons, when it does emerge, is related to response duration, whereas SD responses are taste specific in magnitude. LD responses code palatability, whereas SD responses appear to code reward intensity (e.g., LD neurons code sucrose and $\mathrm{NaCl}$ similarly, $\mathrm{SD}$ neurons code them distinctly). SD taste responses vanish when the taste is self-administered as opposed to experimenter administered, whereas LD taste responses are primarily unaffected by selfadministration. Finally, SD neurons respond to a tone that signals taste availability, whereas LD neurons do not. These results 


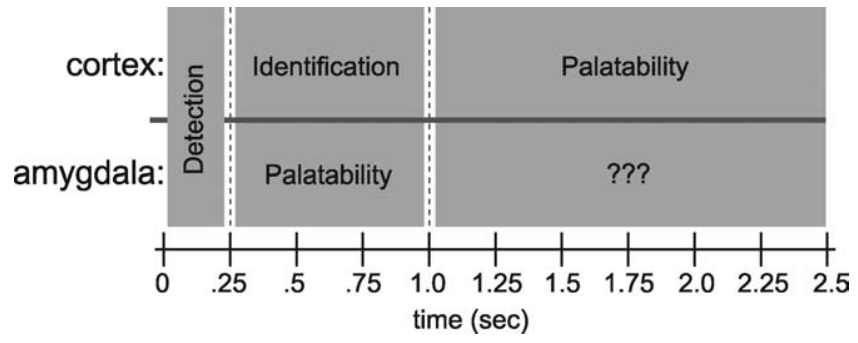

Figure 7. Comparison of results from cortical and LD neurons suggests amygdala- cortical coupling. A schematic of the time courses ( $x$-axis, time after delivery in seconds) of the taste responses observed previously (Katz et al., 2001a) in taste cortex (top) and in LD neurons (bottom) is shown. The two progress through a similarly timed sequence of three response "epochs": one lasting until $\sim 0.25 \mathrm{~s}$, a second lasting from $\sim 0.25$ to $\sim 1.0 \mathrm{~s}$, and a third beginning at $1.0 \mathrm{~s}$ after taste administration. The first epoch appears largely identical for $L D$ and cortical neurons; both provide information about the presence of a taste on the tongue ("Detection") but neither provides discriminative information about which taste is which. Information about palatability is available in LD neurons during the second epoch, whereas cortex conveys information about the identity of the taste regardless of its palatability (i.e., responses to palatability-specific pairs of tastes are not particularly similar). Finally, in the third epoch, palatability-related information appears in cortex, perhaps reflecting transmission from BLA. The third epoch of LD BLA responses remains mysterious at this time.

suggest that LD neurons are a part of the basic taste network that includes GC; SD neurons, meanwhile, are more likely linked to the dopamine reward system.

\section{BLA involvement in hedonic taste processing}

Tastes of similar palatability cause similar responses in amygdalar neurons (Scott et al., 1993; Yasoshima et al., 1995; Nishijo et al., 1998, 2000). Our data demonstrate that this palatability coding is embedded within response dynamics. The initial LD responses are strong in terms of spikes per second but carry no chemosensory information. Palatability coding, first apparent after $250 \mathrm{~ms}$ of processing time, is a function of duration (each neuron's responses to tastes of a particular palatability last longer than responses to tastes of the opposing palatability) and mostly fades within $1 \mathrm{~s}$.

LD response dynamics are highly reminiscent of those observed in GC (Katz et al., 2001a) and confirm our expectation that BLA and GC work together for the purposes of processing tastes. In both regions, tastes elicit responses that change in information content at $\sim 200-250 \mathrm{~ms}$, and again at $\sim 1.0 \mathrm{~s}$ (Fig. 7 ). These two transitions, which occur quite suddenly in single trials (Jones et al., 2007), reflect critical moments dividing the first $2 \mathrm{~s}$ of the taste response into functional epochs (Fontanini and Katz, 2006; Grossman et al., 2008). The early GC neuron responses resemble early LD responses much more than they do SD responses, in that they contain no taste-specific information of any sort (Katz et al., 2001).

LD and GC taste responses are not identical, however. For instance, the somatosensory information that drives some of the early- and late-epoch activity in GC (Katz et al., 2001a) is absent from LD neurons (data not shown). More obviously (Fig. 7), palatability-related information appears in GC only as it vanishes in BLA. These data are in good accord with our recent work showing that taste palatability learning changes early aspects of BLA responses, and later aspects of GC responses (Grossman et al., 2008), and is consistent with a large literature suggesting that BLA's primary job is to evaluate stimulus hedonics (Murray et al., 1993; Scott et al., 1993; Nishijo et al., 2000). The late onset of palatability-related information in GC may reflect the completion of processing in BLA; regardless, the similarity of LD and GC response dynamics suggests cooperativity during processing of a unified taste experience. Such cooperativity has been suggested to facilitate GC's involvement in learning taste-illness associations (Escobar et al., 1998; Escobar and Bermudez-Rattoni, 2000; Miranda et al., 2002; Ferreira et al., 2005; Grossman et al., 2008).

The clear evidence of BLA palatability coding observed here seems, at first blush, to be at odds with some human imaging studies, in which the amygdala seems to respond on the basis of stimulus intensity rather than hedonics (O'Doherty et al., 2001; Small et al., 2003) (but see Zald et al., 1998). Our data offer a simple explanation for this discrepancy. Although LD neurons differentiated pleasant from aversive tastes, there was no observed spatial organization of responses (i.e., sucrose-responsive neurons and quinine-responsive neurons were found in close proximity to each other) (data not shown). It is likely that the voxels of a functional magnetic resonance imaging (fMRI) analysis, each of which covers a relatively large spatial region, will reflect the activity of similar numbers of "palatable-best" and "aversive-best" neurons; thus, responses to strong palatable and unpalatable tastes will cancel each other out in fMRI comparisons.

\section{BLA involvement in processing taste rewards}

When the rat receives tastes passively, SD neurons produce a brief, short-latency burst of action potentials. Responses to different tastes are highly similar in time course but differ markedly in magnitude, such that the amygdala becomes privy to information concerning taste quality well before chemosensory information is available in GC (Katz et al., 2001a).

We propose that SD neurons are likely a part of the reward system, for several reasons. First, just as BLA reward neurons have been shown to code the reward value of stimuli delivered to passive primates (Belova et al., 2007), SD neurons code the reward value of tastes [most SD neurons respond most strongly to the most rewarding taste and least strongly to the most punishing taste (or vice versa), or else respond to both; this latter subtype, observed elsewhere, has been referred to as nonvalenced neurons (Belova et al., 2007)]. Second, just as BLA reward responses are inhibited by self-administration [unexpected cocaine administration induces stronger blood oxygenation level-dependent activation than expected cocaine administration (Kufahl et al., 2008), whereas single-neuron responses to rewarding juice and aversive somatosensory stimuli are inhibited by anticipation (Belova et al., 2007) and shrink with growing predictability (Schoenbaum et al., 1999; Roesch et al., 2007) ], SD responses vanish when the rat lever presses to receive tastes. Emotional responses, meanwhile, are unaffected or even enhanced by anticipation (Bermpohl et al., 2006). Third, just as reward neurons have been shown to respond to stimuli that predict the availability of rewarding stimuli (Mirenowicz and Schultz, 1996), SD neurons respond to a tone announcing taste availability.

Of course, the comparability of this to other datasets is limited. Our rats were unable to predict whether any particular lever press would result in delivery of a rewarding (vs aversive) taste. Thus, the "anticipation" effect observed here is different from that shown in previous studies; we cannot reject the possibility that the striking similarity between SD and classic reward responses would break down if our rats were able to predict which taste was coming. Certainly, we cannot conclusively rule out the possibility that SD tone responses represent motor preparation. We can, however, say that the inhibition of taste responses themselves is unrelated to surprise (passive deliveries are surprising 
and caused robust responses) and motor activity (the lever press occurs well before taste delivery).

The inhibition of SD responses with self-administration may shed new light on the enigmatic finding that BLA lesions/inactivations render rats unable to acquire conditioned taste aversions (CTAs) when tastes are unexpected, while having less effect on their ability to learn CTAs to expected tastes (Schafe et al., 1998; Wang et al., 2006; J. S. Wieskopf and D. B. Katz, unpublished observations). It is possible that SD neuron responses are crucial for amygdalar involvement in CTA and that stimulus anticipation has a significant impact on the circuitry brought to bear on the processing of tastes. Changes in the states of network models affects how information filters through those networks (Jaeger and Bower, 1994; Chance et al., 2002; Santamaria et al., 2002). Such changes, in the taste system, could effectively reroute or "shunt" activity that normally reaches BLA from the dopamine system.

Given the latency of this activity in BLA, it is possible that the normal source of SD responses is the nucleus accumbens, which receives direct input from gustatory brainstem (Hajnal and Norgren, 2005). The same mechanism that keeps SD responses from reaching BLA in the actively sensing rat may, in fact, be the source of early chemosensory information that appears in the GC of rats only when they are obtaining tastes via a lick-spout (Katz et al., 2001a; Stapleton et al., 2006).

\section{Conclusions}

BLA is involved in multiple aspects of taste processing (Berridge, 1996). Here, we show that these interrelated but distinguishable processes are subtended, at least in part, by separable neuron groups. Furthermore, we reveal evidence of cooperation between BLA and other parts of the distributed system involved in taste (in particular, GC) and offer clues to how these processes occur through time as taste information flows through the CNS.

Ultimately, of course, taste stimuli are perceived as wholistic objects for the purposes of feeding (Gibson, 1966). Future work will examine how cortex and amygdala couple together for that purpose, and where in the system [obvious candidates are the orbitofrontal cortex (Saddoris et al., 2005) and central amygdala (Ahn and Phillips, 2002)] the types of information that are separated in BLA converge.

\section{References}

Ahn S, Phillips AG (2002) Modulation by central and basolateral amygdalar nuclei of dopaminergic correlates of feeding to satiety in the rat nucleus accumbens and medial prefrontal cortex. J Neurosci 22:10958-10965.

Balleine BW, Killcross AS, Dickinson A (2003) The effect of lesions of the basolateral amygdala on instrumental conditioning. J Neurosci 23:666-675.

Bauman ML, Kemper TL (2003) The neuropathology of the autism spectrum disorders: what have we learned? Novartis Found Symp 251:112 122; discussion 122-128, 281-297.

Belova MA, Paton JJ, Morrison SE, Salzman CD (2007) Expectation modulates neural responses to pleasant and aversive stimuli in primate amygdala. Neuron 55:970-984.

Bermpohl F, Pascual-Leone A, Amedi A, Merabet LB, Fregni F, Gaab N, Alsop D, Schlaug G, Northoff G (2006) Dissociable networks for the expectancy and perception of emotional stimuli in the human brain. Neuroimage 30:588-600.

Bernard JF, Alden M, Besson JM (1993) The organization of the efferent projections from the pontine parabrachial area to the amygdaloid complex: a Phaseolus vulgaris leucoagglutinin (PHA-L) study in the rat. J Comp Neurol 329:201-229.

Berridge KC (1996) Food reward: brain substrates of wanting and liking. Neurosci Biobehav Rev 20:1-25.

Berridge KC (2000) Measuring hedonic impact in animals and infants: mi- crostructure of affective taste reactivity patterns. Neurosci Biobehav Rev 24:173-198.

Berridge KC, Schulkin J (1989) Palatability shift of a salt-associated incentive during sodium depletion. Q J Exp Psychol B 41:121-138.

Bielavska E, Roldan G (1996) Ipsilateral connections between the gustatory cortex, amygdala and parabrachial nucleus are necessary for acquisition and retrieval of conditioned taste aversion in rats. Behav Brain Res 81:25-31.

Blankenship MR, Huckfeldt R, Steinmetz JJ, Steinmetz JE (2005) The effects of amygdala lesions on hippocampal activity and classical eyeblink conditioning in rats. Brain Res 1035:120-130.

Breslin PAS, Spector AC, Grill HJ (1992) A quantitative comparison of taste reactivity behaviors to sucrose before and after lithium chloride pairings: a unidimensional account of palatability. Behav Neurosci 106:820-836.

Caras ML, Mackenzie K, Rodwin B, Katz DB (2008) Investigating the motivational mechanism of altered saline consumption following 5-HT$\operatorname{sub}$ (1a) manipulation. Behav Neurosci 122:407-415.

Cardinal RN, Parkinson JA, Hall J, Everitt BJ (2002) Emotion and motivation: the role of the amygdala, ventral striatum, and prefrontal cortex. Neurosci Biobehav Rev 26:321-352.

Chance FS, Abbott LF, Reyes AD (2002) Gain modulation from background synaptic input. Neuron 35:773-782.

Corbit LH, Balleine BW (2005) Double dissociation of basolateral and central amygdala lesions on the general and outcome-specific forms of pavlovian-instrumental transfer. J Neurosci 25:962-970.

de Araujo IE, Gutierrez R, Oliveira-Maia AJ, Pereira A Jr, Nicolelis MA, Simon SA (2006) Neural ensemble coding of satiety states. Neuron 51:483-494.

Escobar ML, Bermudez-Rattoni F (2000) Long-term potentiation in the insular cortex enhances conditioned taste aversion retention. Brain Res 852:208-212.

Escobar ML, Chao V, Bermudez-Rattoni F (1998) In vivo long-term potentiation in the insular cortex: NMDA receptor dependence. Brain Res 779:314-319.

Ferreira G, Miranda MI, De la Cruz V, Rodriguez-Ortiz CJ, BermudezRattoni F (2005) Basolateral amygdala glutamatergic activation enhances taste aversion through NMDA receptor activation in the insular cortex. Eur J Neurosci 22:2596-2604.

Fontanini A, Katz DB (2005) 7 to $12 \mathrm{~Hz}$ activity in rat gustatory cortex reflects disengagement from a fluid self-administration task. J Neurophysiol 93:2832-2840.

Fontanini A, Katz DB (2006) State-dependent modulation of time-varying gustatory responses. J Neurophysiol 96:3183-3193.

Ganaraja B, Jeganathan PS (2000) Effect of basolateral amygdala and ventromedial hypothalamic lesions on ingestion and taste preference in rat. Ind J Med Res 112:65-70.

Gibson JJ (1966) The senses considered as perceptual systems. Boston: Houghton Mifflin.

Gilbert PE, Campbell A, Kesner RP (2003) The role of the amygdala in conditioned flavor preference. Neurobiol Learn Mem 79:118-121.

Grill HJ, Norgren R (1978) The taste reactivity test. I. Mimetic responses to gustatory stimuli in neurologically normal rats. Brain Res 143:263-279.

Grossman SA, Fontanini A, Wieskopf JS, Katz DB (2008) Learning-related plasticity of temporal coding in simultaneously recorded amygdalacortical ensembles. J Neurosci 28:2864-2873.

Gruart A, Schreurs BG, del Toro ED, Delgado-Garcia JM (2000) Kinetic and frequency-domain properties of reflex and conditioned eyelid responses in the rabbit. J Neurophysiol 83:836-852.

Hajnal A, Norgren R (2005) Taste pathways that mediate accumbens dopamine release by sapid sucrose. Physiol Behav 84:363-369.

Huang T, Yan J, Kang Y (2003) Role of the central amygdaloid nucleus in shaping the discharge of gustatory neurons in the rat parabrachial nucleus. Brain Res Bull 61:443-452.

Jaeger D, Bower JM (1994) Prolonged responses in rat cerebellar Purkinje cells following activation of the granule cell layer: an intracellular in vitro and in vivo investigation. Exp Brain Res 100:200-214.

Jones LM, Fontanini A, Sadacca BF, Miller P, Katz DB (2007) Natural stimuli evoke dynamic sequences of states in sensory cortical ensembles. Proc Natl Acad Sci U S A 104:18772-18777.

Karimnamazi H, Travers JB (1998) Differential projections from gustatory responsive regions of the parabrachial nucleus to the medulla and forebrain. Brain Res 813:283-302. 
Katz DB, Simon SA, Nicolelis MA (2001a) Dynamic and multimodal responses of gustatory cortical neurons in awake rats. J Neurosci 21:4478-4489.

Katz DB, Simon SA, Nicolelis MAL (2001b) Electrophysiological studies of gustation in awake rats. In: Methods and frontiers in the chemical senses (Simon SA, Nicolelis MAL, eds), pp 339-357. Boca Raton, FL: CRC.

Kufahl P, Li Z, Risinger R, Rainey C, Piacentine L, Wu G, Bloom A, Yang Z, Li SJ (2008) Expectation modulates human brain responses to acute cocaine: a functional magnetic resonance imaging study. Biol Psychiatry 63:222-230.

LeDoux JE (2000) Emotion circuits in the brain. Annu Rev Neurosci 23:155-184.

Li CS, Cho YK, Smith DV (2002) Taste responses of neurons in the hamster solitary nucleus are modulated by the central nucleus of the amygdala. J Neurophysiol 88:2979-2992.

Li CS, Cho YK, Smith DV (2005) Modulation of parabrachial taste neurons by electrical and chemical stimulation of the lateral hypothalamus and amygdala. J Neurophysiol 93:1183-1196.

Lundy RF Jr, Norgren R (2004) Activity in the hypothalamus, amygdala, and cortex generates bilateral and convergent modulation of pontine gustatory neurons. J Neurophysiol 91:1143-1157.

Maren S, Quirk GJ (2004) Neuronal signalling of fear memory. Nat Rev Neurosci 5:844-852.

Maren S, Aharonov G, Stote DL, Fanselow MS (1996) N-methyl-Daspartate receptors in the basolateral amygdala are required for both acquisition and expression of conditional fear in rats. Behav Neurosci 110:1365-1374.

Miranda MI, Ferreira G, Ramirez-Lugo L, Bermudez-Rattoni F (2002) Glutamatergic activity in the amygdala signals visceral input during taste memory formation. Proc Natl Acad Sci U S A 99:11417-11422.

Mirenowicz J, Schultz W (1996) Preferential activation of midbrain dopamine neurons by appetitive rather than aversive stimuli. Nature 379:449-451.

Murray EA, Gaffan D, Mishkin M (1993) Neural substrates of visual stimulus-stimulus association in rhesus monkeys. J Neurosci 13:4549-4561.

Nishijo H, Uwano T, Tamura R, Ono T (1998) Gustatory and multimodal neuronal responses in the amygdala during licking and discrimination of sensory stimuli in awake rats. J Neurophysiol 79:21-36.

Nishijo H, Ono T, Uwano T, Kondoh T, Torii K (2000) Hypothalamic and amygdalar neuronal responses to various tastant solutions during ingestive behavior in rats. J Nutr 130:954S-959S.

Norgren R (1976) Taste pathways to hypothalamus and amygdala. J Comp Neurol 166:17-30.

O'Doherty J (2003) Can't learn without you. Predictive value coding in orbitofrontal cortex requires the basolateral amygdala. Neuron 39:731-733.

O’Doherty J, Rolls ET, Francis S, Bowtell R, McGlone F (2001) Representation of pleasant and aversive taste in the human brain. J Neurophysiol 85:1315-1321.

Oya H, Kawasaki H, Howard MA 3rd, Adolphs R (2002) Electrophysiological responses in the human amygdala discriminate emotion categories of complex visual stimuli. J Neurosci 22:9502-9512.

Pan WX, Schmidt R, Wickens JR, Hyland BI (2005) Dopamine cells respond to predicted events during classical conditioning: evidence for eligibility traces in the reward-learning network. J Neurosci 25:6235-6242.

Pare D, Collins DR (2000) Neuronal correlates of fear in the lateral amygdala: multiple extracellular recordings in conscious cats. J Neurosci 20:2701-2710.

Pare D, Collins DR, Pelletier JG (2002) Amygdala oscillations and the consolidation of emotional memories. Trends Cogn Sci 6:306-314.

Paton JJ, Belova MA, Morrison SE, Salzman CD (2006) The primate amygdala represents the positive and negative value of visual stimuli during learning. Nature 439:865-870.

Paxinos G, Watson C (1997) The rat brain in stereotaxic coordinates, Ed 3. Amsterdam: Academic.

Prather MD, Lavenex P, Mauldin-Jourdain ML, Mason WA, Capitanio JP, Mendoza SP, Amaral DG (2001) Increased social fear and decreased fear of objects in monkeys with neonatal amygdala lesions. Neuroscience 106:653-658.

Pratt WE, Mizumori SJ (1998) Characteristics of basolateral amygdala neuronal firing on a spatial memory task involving differential reward. Behav Neurosci 112:554-570.
Quirk GJ, Repa C, LeDoux JE (1995) Fear conditioning enhances shortlatency auditory responses of lateral amygdala neurons: parallel recordings in the freely behaving rat. Neuron 15:1029-1039.

Reilly S, Bornovalova MA (2005) Conditioned taste aversion and amygdala lesions in the rat: a critical review. Neurosci Biobehav Rev 29:1067-1088.

Repa JC, Muller J, Apergis J, Desrochers TM, Zhou Y, LeDoux JE (2001) Two different lateral amygdala cell populations contribute to the initiation and storage of memory. Nat Neurosci 4:724-731.

Roesch MR, Calu DJ, Schoenbaum G (2007) Dopamine neurons encode the better option in rats deciding between differently delayed or sized rewards. Nat Neurosci 10:1615-1624.

Saddoris MP, Gallagher M, Schoenbaum G (2005) Rapid associative encoding in basolateral amygdala depends on connections with orbitofrontal cortex. Neuron 46:321-331.

Santamaria F, Jaeger D, De Schutter E, Bower JM (2002) Modulatory effects of parallel fiber and molecular layer interneuron synaptic activity on purkinje cell responses to ascending segment input: a modeling study. J Comput Neurosci 13:217-235.

Schafe GE, Thiele TE, Bernstein IL (1998) Conditioning method dramatically alters the role of amygdala in taste aversion learning. Learn Mem 5:481-492.

Schoenbaum G, Chiba AA, Gallagher M (1998) Orbitofrontal cortex and basolateral amygdala encode expected outcomes during learning. Nat Neurosci 1:155-159.

Schoenbaum G, Chiba AA, Gallagher M (1999) Neural encoding in orbitofrontal cortex and basolateral amygdala during olfactory discrimination learning. J Neurosci 19:1876-1884.

Schoenbaum G, Setlow B, Nugent SL, Saddoris MP, Gallagher M (2003) Lesions of orbitofrontal cortex and basolateral amygdala complex disrup acquisition of odor-guided discriminations and reversals. Learn Mem 10:129-140.

Schultz W (2001) Reward signaling by dopamine neurons. Neuroscientist 7:293-302.

Schultz W, Dayan P, Montague PR (1997) A neural substrate of prediction and reward. Science 275:1593-1599.

Scott TR, Karadi Z, Oomura Y, Nishino H, Plata-Salaman CR, Lenard L, Giza BK, Aou S (1993) Gustatory neural coding in the amygdala of the alert macaque monkey. J Neurophysiol 69:1810-1820.

Small DM, Gregory MD, Mak YE, Gitelman D, Mesulam MM, Parrish T (2003) Dissociation of neural representation of intensity and affective valuation in human gustation. Neuron 39:701-711.

St Andre J, Reilly S (2007) Effects of central and basolateral amygdala lesions on conditioned taste aversion and latent inhibition. Behav Neurosci 121:90-99.

Stapleton JR, Lavine ML, Wolpert RL, Nicolelis MA, Simon SA (2006) Rapid taste responses in the gustatory cortex during licking. J Neurosci 26:4126-4138.

Tokita K, Karadi Z, Shimura T, Yamamoto T (2004) Centrifugal inputs modulate taste aversion learning associated parabrachial neuronal activities. J Neurophysiol 92:265-279.

Touzani K, Sclafani A (2005) Critical role of amygdala in flavor but not taste preference learning in rats. Eur J Neurosci 22:1767-1774.

Touzani K, Taghzouti K, Velley L (1997) Increase of the aversive value of taste stimuli following ibotenic acid lesion of the central amygdaloid nucleus in the rat. Behav Brain Res 88:133-142.

Tye KM, Janak PH (2007) Amygdala neurons differentially encode motivation and reinforcement. J Neurosci 27:3937-3945.

Veening JG (1978) Subcortical afferents of the amygdaloid complex in the rat: an HRP study. Neurosci Lett 8:197-202.

Wang Y-Y, Fontanini A, Katz DB (2006) Temporary basolateral amygdala lesions disrupt acquisition of socially transmitted food preferences in rats. Learn Mem 13:794-800.

Yamamoto T, Azuma S, Kawamura Y (1984) Functional relations between the cortical gustatory area and the amygdala: electrophysiological and behavioral studies in rats. Exp Brain Res 56:23-31.

Yasoshima Y, Shimura T, Yamamoto T (1995) Single unit responses of the amygdala after conditioned taste aversion in conscious rats. Neuroreport 6:2424-2428.

Zald DH, Lee JT, Fluegel KW, Pardo JV (1998) Aversive gustatory stimulation activates limbic circuits in humans. Brain 121:1143-1154. 